\title{
Regulatory Treatment of IP Transport and Services
}

\author{
Joshua L Mindel and Marvin A. Sirbu
}

Introduction

Current U.S. regulatory policy is incoherent in its treatment of packet-oriented data communications services. Services based on X.25, Frame Relay or ATM protocols are regulated as telecommunications services, while IP packet transport is lumped together with applications such as email and the World Wide Web -- and treated as an unregulated information service. Uncertainty also reigns over the appropriate treatment of IP telephony. As IP transport becomes an ever more significant fraction of all telecommunications, public policy problems posed by this inconsistent treatment are likely to increase.

In this chapter, we undertake a thought-experiment in which we consider the consequences that would ensue, under existing legislation, if the Federal Communications Commission were to reclassify IP transport as a telecommunications service, while continuing to treat most applications which run over IP as information services. We do not recommend that such a reclassification be taken, but rather seek to understand the obligations and benefits that such a reclassification might trigger.

We systematically examine the rights and obligations that apply to telecommunications service providers, particularly under Section 251 of the Telecommunications Act, identifying which obligations make sense for IP transport providers, and which might be waived under the Commission's forbearance authority as unnecessary given the intensely competitive nature of the IP transport market. Internet telephony is an application which rides on top of IP transport. We also examine those Section 251 rules which apply specifically to telephony and consider how they might be applied to IP telephony providers.

We conclude the following: 1) Reclassification of IP transport, and telephony services over IP transport, would have immediate benefits for some ISPs; 2) Some Section 251 obligations would only be needed if a dominant provider emerges; and 3) Many obligations could be waived under the Commission's authority to waive unnecessary regulations. We also raise concerns that such a reclassification may trigger new, potentially unnecessary, obligations under State laws where Commission forbearance is not an option. Additional analyses, beyond the scope of this research, are needed to evaluate other obligations (e.g. Universal Service Funding) triggered by these potential reclassifications.

\section{Background}

Title I of the U.S. Telecommunications Act states its purpose as "regulating interstate and foreign commerce in communication by wire and radio so as to make available... a rapid, efficient, Nation-wide, and world-wide wire and radio communication service with adequate facilities at reasonable charges...." [1] The legislation goes on to define a variety 
of activities that are to be subject to the Act, including telecommunications, telecommunications service, and exchange access as well as categories of companies such as telecommunications carrier and local exchange carrier.

As with any piece of legislation, the definitions of these terms are crucial, for they determine which firms and which services are to be regulated, and what obligations or prescriptions will be imposed. Since the early 1960s, the U.S. Federal Communications Commission, which enforces the Act, has wrestled with the question of the boundary between telecommunications services--which are to be regulated under the Act--and computer or information services, which fall outside the Act's regulatory jurisdiction.

The origins of the current telecommunications vs. information services boundary can be traced back to the 1956 Consent Decree, in which AT\&T agreed to restrict itself to the business of "regulated communications", and, by implication, not to participate in the burgeoning computer industry. The Commission launched its First Computer Inquiry in 1966 to distinguish between regulated communications and computers connecting to telephone lines. The regulatory boundary started to take its current shape with Computer Inquiry II, which defined basic and enhanced services. Basic service was defined as a pure transmission service offered by a regulated telecommunications carrier over a communications path that is virtually transparent in terms of its interaction with customer supplied information. Enhanced service was defined as a service offered over common carrier transmission facilities that employed computer processing applications that modified the subscriber's transmitted information, or involved subscriber interaction with stored information. The Commission determined that while it held jurisdiction over both basic and enhanced services, it would not serve the public interest to regulate enhanced services since they were competitive.

These concepts were further refined in the Telecommunications Act of 1996, which defines both Telecommunications service and Information services. Telecommunications is defined in the Act as "the transmission, between or among points specified by the user, of information of the user's choosing, without change in the form or content of the information as sent and received." Telecommunications service means "the offering of telecommunications for a fee directly to the public...." In contrast, Information service is defined as those services that do change the form or content, and that do not affect the management, control, or operation of a telecommunications system or the management of a telecommunications service [2].

On the face of it, IP transport -- that is the transport of Internet Protocol packets between points specified by the user and containing information of the user's choosing --would appear to meet the criteria for a telecommunications service. However, for historical reasons, the services provided on the Internet (e.g. email, world wide web, Netnews), as well as simple IP transport have been classified as information services and thus remain outside the scope of telecommunications service regulations.

This result has increasingly been recognized as providing inconsistent treatment for very similar services. Thus, data communications services provided using the X.25, 
Asynchronous Transfer Mode (ATM) or Frame Relay protocols are classified as telecommunications services, whereas IP transport is not.

Figure 1.1 portrays a variety of services along a continuum, illustrating the boundary between unregulated services and telecommunications services whose providers have specific obligations and benefits. Communications via circuit-switched communications and via several packet-switched communications technologies (e.g. X.25, ATM, Frame Relay) are categorized as telecommunications services. Communications via IP packetswitched networks are categorized as information services. This inconsistent treatment of packet-switched technologies dilutes or blurs the meaningfulness of the regulatory boundary depicted in Figure 1.1 .

\section{$<$ Insert figure 1.1 here $>$}

Over the past three years, the Federal Communications Commission (the Commission) has published two Working Papers, one Report to Congress, and numerous Orders and Notices that explicitly discuss these regulatory difficulties [3-6]. A few independently published papers directly address the issue as well [7].

Attention has been focused on this definitional incoherence, as it becomes apparent that IP transport will, over the next decade, become the predominant "service" provided over the nation's telecommunications networks. Data communications, and particularly data sent using IP, is rapidly eclipsing circuit-switched voice traffic in terms of the number of bits carried over telecommunications networks. Firms regulated as telecommunications service providers, or telecommunications carriers, carry obligations such as interconnection, nondiscrimination, and contributions to the Universal Service Fund (USF). These obligations ensure that related public policy goals are met. Firms classified as information service providers do not have these obligations. As unregulated IP transport providers displace existing telecommunications carriers, these public policy goals may be threatened.

At the same time, there are many in the Internet industry, Congress and the Commission who have been very vocal in their insistence that the Internet should not be regulated in the same way as telecommunications carriers. Kende [8] "argues that any traditional telecommunications regulation of Internet backbone interconnection is made unnecessary by a competitive backbone market. ..." Some fear that government regulation will stifle the innovation and investment that characterize the industry today. Still, others observe that government intervention, particularly investment in public goods such as R\&D, has been extremely beneficial to the IP transport sector: e.g. ARPAnet ${ }^{1}$, NSFnet ${ }^{2}$, InterNIC ${ }^{3}$, $\mathrm{NAPs}^{4}$, and vBNS/Internet 2. ${ }^{5}$ Oxman [9] presents a summary of Commission rulings that have benefited IP-related services.

Regulation designed for a telecommunications industry characterized by franchise or de facto monopolies may not be appropriate for the vigorously competitive Internet industry. Indeed, the earliest regulation of telephony by the Interstate Commerce Commission (ICC) was designed to limit the power of telecommunications monopolies over pricing, interconnection, and entry. As parts of the industry--such as interexchange--became competitive, the Commission continued to closely regulate the behavior of dominant carriers. Much of the current regulatory debate is focused on how much to regulate the 
dominant incumbent local exchange carriers (ILECs) as we move towards competition in the local exchange. By contrast, no single ISP dominates the Internet to the extent that AT\&T once dominated telephony.

Objective of this paper

Our paper is motivated by the problem of blurred boundaries and inconsistent regulation of IP transport, as compared to other data communications services. Short of asking Congress to pass new legislation, can the Commission address the problem using the powers already granted to it under the ' 96 Telecommunications Act?

One course of action the Commission might take is to redefine IP transport as a telecommunications service. Figure 1.2 portrays the shifted regulatory boundary that would result from this redefinition. Such a reclassification would trigger a range of obligations upon Internet Service Providers (ISPs) for which they have been heretofore exempt. It would also allow ISPs to benefit from the rights to which telecommunications service providers are entitled. As noted above, many of these obligations or restrictions were motivated by concerns over potential abuse of market power by telecommunications carriers. Under Section 10 of the Act [11], the Commission is authorized to waive many of the regulations required by the Act if a competitive marketplace is sufficient to protect consumers' interests.

\section{$<$ Insert figure 1.2 here $>$}

Conceptually, therefore, we are interested in examining the following scenario. Suppose that the Commission defines IP transport as a new category of telecommunications service. Further, suppose that the Commission then chooses to use its forbearance authority to forbear from any unnecessary regulation that would be triggered by such a reclassification. What would be the implications of such a scenario? In particular, what would be the implications of such an action with respect to the issues of interconnection among IP transport providers and on unbundling of telecommunications services? Other rules triggered by the reclassification of IP transport, such as USF obligations, are beyond the scope of this paper.

\section{Outline and Approach}

The IP Transport and Section 251 section of this paper contains the results of an analysis that looked at how Section 251 (Interconnection) of the Act could be applied to IP transport. The Telephony over IP Transport section contains the results of a similar analysis that looked at IP telephony over IP transport. The interconnection rules that apply to all telecommunications carriers are of most interest. The unbundling rules for LECs, ILECs, and the Bell Operating Companies (BOCs) are based on limiting their exercise of monopoly power. These are less relevant to IP transport providers where there are no comparable dominant providers. LECs themselves can be viewed as the creation of an earlier unbundling decision. ${ }^{6}$ 
The analyses are technical, qualitative, and systematically applied to each of the interconnection and unbundling rules for telecommunications carriers. The first step is to clarify the underlying policy concern and review how this concern is addressed for telecommunications carriers. The next phase identifies the equivalent policy concern that exists for the provision of IP transport services, and reviews how this concern is currently handled by IP transport providers. The third phase is a thought experiment in which realistic situations are identified under which specific obligations might be mandated, or where the Commission should prefer to forbear. Table 1.1 shows the template used for the analysis.

\section{$<$ Insert table 1.1 here $>$}

Three tenets support this analysis: 1) IP transport services are distinct from applications that use IP transport services; 2) Interconnection and unbundling are motivated by different underlying economic forces and policy goals; and 3) History provides insight. Interconnection requirements are motivated by a desire to maximize positive network externalities, whereas unbundling requirements exist to restrict dominant firms from exercising market power through bundling.

The interconnection and unbundling rules in the amended Communications Act of 1934 (the $A c t$ ) are organized into four hierarchically related sets, plus one additional rule set for the Commission itself. The first rule set applies to all telecommunications carriers. The first two rule sets apply to all LECs. The first three rule sets apply to all incumbent LECs. Finally, the first four rule sets apply to the BOCs. All of the rule sets are referred to as interconnection rules in the Act, though only the first and last sets are actually interconnection rules. The other rule sets focus on LEC unbundling. Table 1.2 lists the specific data sources in the Act.

$<$ Insert table 1.2 here $>$

IP Transport and Section 251

Only a few of the Act's requirements for interconnection among carriers have a reasonable interpretation when applied to IP transport providers. Where they do not, these requirements should be waived using the Commission's authority to forbear from regulation. Table 1.2 (above) identifies the sections in the Act that contain the interconnection and unbundling requirements. We discuss below several issues that deserve detailed consideration.

\section{Interconnect with Facilities of Other Carriers}

Each telecommunications carrier has the duty to interconnect directly or indirectly with the facilities ... of other telecommunications carriers [13].

The duty to interconnect ensures that users can benefit from the positive externalities derived from a large interconnected pool of users. In the PSTN, LECs interconnect directly 
with IXCs via points-of-presence (POPs). Competitive Access Providers (CAPs) or Competitive Local Exchange Carriers (CLECs) may bypass a LEC and directly connect to an IXC, or may directly connect to an LEC at tandem switches or end offices. Through this web of connections, all PSTN carriers are interconnected either directly or indirectly.

Functionally, to interconnect in the PSTN implies both an exchange of content (voice, data, or fax) and an exchange of signaling information for call setup and takedown. This is made possible by a $64 \mathrm{Kbps}$, digital, circuit-switched network to carry voice/data/fax, and a separate packet-switched network to carry signaling information for call setup and routing.

In addition to the PSTN, there is a group of data services classified by the Commission as telecommunications services which appear subject to these interconnection obligations: X.25, ATM, and Frame Relay. Interestingly, though, the Commission has not explicitly addressed this requirement, despite the current paucity of Frame Relay and ATM network interconnection. While the Commission could address the lack of interconnection sua sponte, it generally prefers to wait until it receives a complaint or a petition for rulemaking. Despite the lack of interconnection, no such complaint has surfaced.

The policy concern for IP transport providers is essentially the same, except the network externalities are derived from the interconnection of both users and resources (e.g. online content). IP transport services interconnect via public (multilateral) and private (typically bilateral) traffic exchange points. Public traffic exchanges take place via NAPs, Metropolitan Area Exchanges (MAEs), and commercial Internet exchanges (CIX). To illustrate IP transport network interconnections, Figure 1.3 depicts the multiple networks that might be traversed when a user browses a remote web site.

\section{$<$ Insert figure 1.3 here $>$}

At the present time, all IP transport providers partake in interconnection agreements on a voluntary basis. For best-effort service networks, the interconnection arrangements are for peering or transit. Peering is an arrangement in which both service providers agree to: 1) Accept all traffic from the other; 2) Only forward traffic destined for the receiving network, or for downstream customers of that network; and 3) Exchange traffic without settlements.

In lieu of peering, a hierarchical arrangement called transit is available in which an upstream IP provider: 1) Accepts all traffic from the downstream provider, and agrees to forward it to its destination, whether or not that destination is on its network; and 2) Receives payment from the downstream provider. Technologically, peering and transit policies are implemented in the form of configuration information for the Border Gateway Protocol (BGP-4). BGP-4 is used to exchange routing information among ISPs [14].

Larger providers have incentives to withhold peering below certain thresholds of connectivity (e.g. multiple Network Access Points - NAPs, minimum traffic loads), and instead offer transit. Milgrom et al. [15] and others [16-18] discuss these incentives both quantitatively and qualitatively. The multiple NAP requirement can be viewed as an unbundling of the smaller IP transport provider's network to help the larger network reduce free-riding by the smaller network. Smaller providers argue that larger providers discriminate by offering peering to some providers and not to others. The Commission has 
issued a Notice of Inquiry (NOI) that, among other issues, asked whether there was a perceived need for Commission regulation of peering [6]. ${ }^{7}$

Within a few years, peering vs. transit issues will likely be overshadowed by the Service Level Agreements (SLAs) that will be required to interconnect QoS capable networks [17]. An SLA will include a characterization of the treatment that the customer's traffic will be afforded (e.g. throughput, latency, packet loss rate), any traffic conditioning rules that must be adhered to by the customer in order to receive the specified treatment, measurement methods to verify compliance, and the price to be paid for the contracted level of service. SLAs will be negotiated by end users with ISPs, and by ISPs with each other in order to recursively provide end-to-end QoS for the end user's traffic as it crosses multiple ISPs.

The Internet Engineering Task Force and the Internet2 QBone Working Group are developing the DiffServ QoS architecture $[19,20]$. The technologies are not yet mature enough for commercial deployment. With DiffServ, a Bandwidth Broker (BB) is an infrastructure component that coordinates provision of QoS IP transport service requests. User requests are sent to the $\mathrm{BB}$ and then to the appropriate router. BBs keep track of the current allocation of marked traffic and interpret new requests in light of policies (e.g. priorities) and current allocations. BBs will coordinate the setup and maintenance of bilateral service agreements for provision of QoS IP transport services across multiple providers. ${ }^{8}$ Standardized information models are also being defined to ensure that policies and service definitions can be interpreted consistently across multiple provider networks $[22,23]$. These standards are required to enable a subscriber to request an end-to-end QoS service that may (knowingly or unknowingly to the subscriber) be delivered via multiple providers' networks.

Policy Implications. To date, interconnection among IP transport providers has occurred entirely through voluntary agreements. The incentives for IP transport providers to cooperate and/or compete are far more complex, however, than they were in earlier phases of the Internet when fewer IP transport providers existed and user demand was weaker. There have been some complaints by smaller carriers that have been forced to purchase transit when they desired settlement-free peering.

In the absence of a single dominant ISP, all players have an economic incentive to interconnect in order to realize network externalities. To ensure that even dominant ISPs will voluntarily interconnect, the Commission could adopt a number of policies that are far short of the mandated pricing or Commission-as-arbitrator that characterizes regulation of interconnection among existing telecommunications carriers. For example, the Commission could:

- $\quad$ Require that ISPs establish publicly posted criteria for when another ISP is entitled to peering versus transit. ${ }^{9}$

- Require public disclosure of interconnection agreements.

- Require ISPs to offer other ISPs the same SLAs that they offer to end user customers. This is equivalent to allowing an ISP customer to resell the services 
implied by an SLA. In addition, an ISP may offer additional services to other ISPs that it does not offer to end user customers.

- Establish default technical standards if voluntary industry consensus processes are unable to reach agreement on interconnection standards. ${ }^{10}$

Resale

The duty not to prohibit, and not to impose unreasonable or discriminatory conditions or limitations on, the resale of its telecommunications services [24].

The duty to provide resale is imposed on all local exchange carriers. A LEC is a carrier that provides telephone exchange service or exchange access service. The former, in turn, is defined as:

A. Service within a telephone exchange, or within a connected system of telephone exchanges within the same exchange area operated to furnish to subscribers intercommunicating service of the character ordinarily furnished by a single exchange, and which is covered by the exchange service charge; or

B. Comparable service provided through a system of switches, transmission equipment, or other facilities (or combination thereof) by which a subscriber can originate and terminate a telecommunications service [2].

If IP transport is classified as a telecommunications service, then, within an exchange area, an ISP would appear to satisfy part 2) of the definition of an LEC. Such an IP transport provider would be subject to the requirements of Section $251 \mathrm{~b}$ ) of the Act, which includes, among others, a requirement to allow other carriers to resell its services.

The Commission first began to mandate resale of telecommunications services in 1976 when it approved the application of Telenet Corporation to resell leased line service by the packet. AT\&T had originally banned resale because it undermined flat rate residential service. In the mid-90's some ISPs attempted to ban resale for the same reason, but were forced to relent due to competition. More recently, cable modem service providers, such as Comcast, have banned resale as part of their tariffs. ${ }^{11}$

Mandatory resale has been viewed by regulators as a means to reduce opportunities for price discrimination by a dominant carrier by encouraging resale arbitrage of its services. It also provides competing carriers another avenue to achieve network ubiquity short of all new construction.

Reclassification of IP transport as a telecommunications service would require Internet local access providers, e.g. Comcast, to permit resale of their services by competing ISPs.

The response of AT\&T to mandatory resale was to shift from flat rate pricing schemes such as its WATS long distance tariff to metered usage pricing. A similar response could be expected from IP access providers, either through packet counting (e.g. burstable service), or the introduction of multiple tiers of service offering different throughput levels. 
Alternatively, the Commission could choose to waive this requirement on the grounds that, given the intense competition among Internet local access providers, price discrimination is not possible in the first place, so mandatory resale is unnecessary to discipline prices.

\section{Reciprocal compensation}

The duty to establish reciprocal compensation arrangements for the transport and termination of telecommunications [24].

ISPs who qualify as LECs would be obliged under this clause to provide reciprocal compensation when exchanging traffic with other ISPs at a local NAP. This would require detailed traffic accounting which is not typically done today. It would also make it impossible for a local ISP to buy transit from a backbone ISP that was also a local competitor. Given the history in the Internet of interconnection without detailed accounting, it would make sense for the Commission to waive the reciprocal compensation obligation.

Numbering Administration

The Commission shall create or designate one or more impartial entities to administer telecommunications numbering ... [25].

Numbering administration ensures that a consistent and nondiscriminatory method of telecommunications numbering is used that enables unique and routable telecommunications. The Act provides the Commission with responsibility for supervising numbering administration for telecommunications services [25]. In POTS, historically, there has been a single number (or name or address) space of the format: xxx-yyy-zzzz. ${ }^{12}$ In IP transport, there are three name spaces: Domain names, IP addresses, and hardware addresses. Names and addresses are abstractions used to identify entities. As depicted in Figure 1.4, names imply a higher level of abstraction than addresses.

\section{$<$ Insert figure 1.4 here $>$}

The Act gives the Commission authority to designate an administrator of telecommunications numbers. For POTS, it is the North American Numbering Plan administrator. Currently, the highly controversial, private, non-profit Internet Corporation for Assigned Names and Numbers (ICANN) manages domain names and IP addresses along with the American Registry of Internet Numbers (ARIN) which assigns IP addresses. If IP transport is reclassified as a telecommunication service, ARIN, and perhaps ICANN, will come under the purview of the Commission. 
Number Portability

The term number portability means the ability of users of telecommunications services to retain, at the same location, existing telecommunications numbers without impairment of quality, reliability, or convenience when switching from one telecommunications carrier to another [2].

Historically, telephone numbers have corresponded directly to a physical line card in a telephone switch at a LEC CO. There was a single name space. Number portability is achieved by establishing a new name space of logical telephone numbers and mapping each of them to a physical line card address space. ${ }^{13}$ Separation of the physical line card number from a logical number is a form of unbundling. This unbundling makes it "less expensive and less disruptive for a customer to switch providers, thus freeing the customer to choose the local provider that offers the best value." [26] A user can change carrier and thus physical number while advertising the same logical phone number. Switching costs are primarily due to advertising to other telephone and fax users that their telephone number has changed.

A lack of number portability for IP transport networks also raises switching costs.

As with the PSTN, higher-level names are more stable than lower level names. Email addresses and web page links typically use domain names to refer to host computers. IP network nodes use IP addresses to communicate in an IP transport network. If a host's IP address changes, the mapping between the domain name and IP address is changed. Whether an IP address is defined dynamically or statically depends on the type of network node and how it is configured.

Since the early 1990's, when the number of Internet hosts and networks began to grow at a rapid rate, the Internet has implemented a hierarchical IP address space that reflects the overall Internet topology [27]. The hierarchy permits route aggregation (via Classless InterDomain Routing - CIDR) that limits the growth rate of the number of routes that are maintained in the routing tables of the core backbone networks [28]. ${ }^{14}$ The hierarchy also creates a dependency between upstream providers that allocate IP address blocks and downstream customers that use the IP address blocks. ${ }^{15}$ This addressing scheme does not permit number portability for all IP transport providers because the IP address block is not portable. Service providers at the top of the IP address space hierarchy have portable IP address blocks.

When a downstream provider switches upstream providers, it incurs the switching cost of renumbering its IP addressable devices. These switching costs can constitute a barrier to entry for potential upstream providers [30]. These costs take the form of increased operational and coordination costs, rather than the advertising costs associated with a lack of number portability in the PSTN. A downstream provider will need to renumber its own equipment (e.g. routers, DNS servers), as well as coordinate with its downstream customers to renumber their equipment as well. Automated configuration protocols, such as the 
Dynamic Host Configuration Protocol (DHCP) in IPv4, and the auto configuration and neighbor discovery protocols in IPv6 reduce switching costs.

Figure 1.5 depicts an example of the renumbering that a customer will need to undergo when switching from one upstream provider to another. ${ }^{16}$ In both cases the customer has an address block of 2048 IP addresses; with provider A they range from 190.10.80.0 to 190.10.87.255, and with provider B they range from 175.25.96.0 to 175.25.103.255.

\section{$<$ Insert figure 1.5 here $>$}

If a downstream customer is an end user that uses the domain name provided by the upstream provider, then switching costs include advertising as well. However, this is not a public policy concern since portable domain names are easily available.

If IP transport is classified as a telecommunications service, the obligation for number portability will apply to IP transport providers. If this requirement is seen to apply to domain names, rather than to IP addresses, there is little difficulty in preserving a domain name while switching ISPs. A requirement that all IP addresses be portable would have a significant negative impact on ISP routing costs and is not currently in the public interest. One of the few actions the Commission could take would be to promote or mandate the rapid adoption of Ipv6 to reduce (though not eliminate) switching costs.

\section{Access to Rights-of-Way}

The duty to afford access to the poles, ducts, conduits, and rights-of-way of such carrier to competing providers of telecommunications services on ... terms ... that are consistent with section 224 [24].

The term pole attachment means any attachment by a cable television system or provider of telecommunications service to a pole, duct, conduit, or right-of-way owned or controlled by a utility [31].

The term utility means any person who is a local exchange carrier or an electric, gas, water, steam, or other public utility, and who owns or controls poles, ducts, conduits, or rights-of-way used ... for any wire communications. Such term does not include any railroad ... [31].

The unbundling of rights-of-way reduces the barriers to entry that competitors face in deploying transmission equipment for the provision of telecommunications services. By contrast, IP transport providers are not afforded the same nondiscriminatory access to rights-of-way.

Metricom, for example, is widely deploying small radios to provide wireless Internet access service. In a recent filing to the Commission, Metricom stated that some of the obstacles it faces in negotiating agreements with public utility companies (that own 
streetlights and power distribution poles located in the public right-of-way) exist because of its limited rights as an information service provider [32].

The simple act of reclassifying IP transport as a telecommunications service would solve Metricom's problem; as a telecommunications service provider it would automatically be entitled to benefit from the pole attachment and related provisions of the Act.

\section{Telephony over IP Transport}

Historically, the telecommunications industry grew up tightly coupled with telephone exchange services. Legislation for the telecommunications industry defined telecommunications in terms of the technology used to provide the services; e.g. telephone exchange service, call routing, etc. As computer communications grew in the 1960's, the associated legislation became more general - referring to telecommunications services, rather than to telephone services. In some places, the Communications Act refers to specific services and in others it doesn't. For example, as noted above, the definition of telephone exchange service starts out referring to telephone service, but as subsequently modified, refers more generally to any telecommunications service. As a whole, the Communications Act has only partially graduated from the language of the telephone industry to the language of the telecommunications industry.

Today, we have IP telephony and multimedia calls that share some of the same characteristics as telephone exchange service (from a user's perspective), yet bear little resemblance from technological infrastructure or industrial organization perspectives. When services specifically identified in the Act, such as telephony, are provided over an IP transport provider's network, how should these services be treated from a regulatory perspective? Defining IP transport as a telecommunications service says nothing about the end-to-end services that might run over such a transport capability. See Figure 1.6..

\section{$<$ Insert figure 1.6 here $>$}

For example, Dialink corporation, using software and CPE from Netergy Networks, proposes to offer local exchange telephone service over any broadband local IP transport provider's network. ${ }^{17}$ Voice packets will go directly from CPE to CPE over the IP transport infrastructure, while call setup is handled by communication between the CPE and a server managed by Dialink and running at the Exodus web hosting site. In this example, depicted in Figure 1.7, who is providing the exchange? Is it the IP transport provider whose application-neutral transport enables CPE to communicate? Or is it Dialink that is providing crucial call setup functionality, but neither transmission nor switching?

\section{$<$ Insert figure 1.7 here $>$}

It is useful to examine some of the rules designed to foster interconnection between incumbent LECs and emerging competitors, and explore what would be the equivalent when Voice over IP (VoIP) is provided as described above. 
Access to Directory Information

The duty to provide ... competing providers ... nondiscriminatory access to telephone numbers, ...directory assistance, and directory listing, with no unreasonable dialing delays $[24,33]$.

White pages directory listings for customers of the other carrier's telephone exchange service [33].

The unbundling of directory information reduces the barrier to entry that a competitor faces. Equivalent policy concerns will be raised for IP telephony when these services become viable substitutes (and competitors) for POTS.

IP transport applications use an Internet-wide, hierarchical, and distributed directory called the Domain Name System (DNS) to map between domain names and IP addresses. The draft ENUM standard, which will provide mappings between the ITU E.164 telephone numbers used in POTs and the IP address based telephony numbers, proposes a DNS-based architecture [34].

IP telephony providers will also need to be able to have their subscribers listed with Directory Assistance and appear in the White Pages.

Access to Signaling for Call Routing and Completion

Nondiscriminatory access to databases and associated signaling necessary for call routing and completion [33].

The unbundling of call signaling in the PSTN is important to enable competitors to deploy telephony services without having to deploy the full cost of a redundant, out-of-band signaling system called Signaling System 7 (SS7) / Advanced Intelligent Network (AIN) [26]. Based on historical precedent, attention must be paid to which signaling elements are unbundled to ensure that competitors have access to all elements necessary for "peer" interconnection, rather than the more limited access afforded to customers that do not resell service. ${ }^{18}$ The availability of unbundled signaling may influence the deployment of IP telephony services. Figure 1.8 depicts an example of unbundled signaling.

\section{$<$ Insert figure 1.8 here $>$}

A related issue with public policy overtones is the extent to which end users can manage and control telephony signaling [36,37].

VoIP clearinghouses are emerging that lower the barriers to entry for IP telephony providers by enabling them to originate calls and hand them off to the clearinghouse for termination; as well as receive calls to terminate from the clearinghouse [29]. 
Nondiscriminatory access to 911 and E911 services ... [33].

The unbundling of emergency services reduces the cost of providing a competing service. In the PSTN, the implementation of a 911 service requires that there be a mapping available between the calling party's telephone number and a physical location (e.g. street address). Cellular PCS uses either a network-based solution (e.g. triangulation) or a handset-based solution (e.g. Global Positioning System - GPS) to provide the E911/911 service center with the latitude and longitude of the caller's location. There will be an equivalent policy concern for IP telephony when it is considered a substitute for POTS. Implementation of a 911 service for IP telephony will require a mapping between the IP address of the device placing the call and the user's registered location. For mobile IP telephony, this implies a mapping that is frequently updated.

Today, only certificated LECs are entitled/obliged to participate in E911 systems. In the future, it must be possible for ASPs like Dialink to participate as well. It does not appear to make sense to require Dialink to seek certification as an LEC. The Commission might also want to mandate that E911 centers be able to receive VoIP calls as IP without first going through a gateway to convert them to traditional circuit-switched calls. The Commission might also want to promote standards development for interconnecting IP telephone services to the E911 database.

\section{Conclusions}

At the beginning of this paper we asked what if IP transport was classified as a telecommunications service. We've looked at interconnection and unbundling obligations that might be applicable. We recall that the Commission has authority under Section 10 of the Act to waive unnecessary obligations. So, in looking at the policy implications of reclassifying IP transport as a telecommunications service, we looked at what benefits were realized and where the Commission would best waive requirements that are unnecessary.

We found that in the absence of a dominant IP transport provider with market power, many of the obligations and duties levied on traditional carriers could be waived for IP transport providers. In other cases, we found that mere reclassification of IP transport as a telecommunications service solved problems being experienced by some ISPs, such as access to right-of-way.

We should note that there are a number of significant reasons why the Commission might hesitate to pursue the scenario examined in this paper. Among other obligations that would be triggered by reclassifying IP transport as a telecommunications service, there are extensive reporting requirements, not all of which the Commission has the authority to waive.

Second, while Section 10 of the Act forbids State Commissions from enforcing any provisions of the Act that the Commission has decided to forbear from, the Act does not preclude State Commissions from applying their own provisions to telecommunications 
services. This implies that reclassifying IP transport services as telecommunications services exposes IP transport providers to State obligations unless State or new Federal legislation allows these to be pre-empted [38].

Third, it is possible that a heightened concern for regulation will limit investment in the Internet and future innovation in services.

Finally, there is concern that, given the rapid rate of technological change, it will be impossible for the Commission to ensure that it has or maintains the correct degree of regulation and/or forbearance.

This analysis serves as a starting point for redefining the telecommunications vs. information services boundary. A case can be made for reclassifying IP transport as a new subcategory of telecommunications service while waiving unnecessary interconnection and unbundling obligations that would otherwise be triggered. Many obligations could be waived as unnecessary given the competitive nature of the ISP industry. Additional analyses, beyond the scope of this paper, need to evaluate other obligations triggered by the reclassification of IP transport. 
Bibliography

[1] Congress, "Communications Act of 1934," One Hundred and Fourth Congress of the United States, Washington, D.C., 1996.

[2] Congress, "Definitions," in Communications Act of 1934. Washington, D.C.: One Hundred and Fourth Congress of the United States, 1996, Sec. 3.

[3] B. Esbin, "Internet over Cable: Defining the Future in Terms of the Past," Office of Plans \& Policy, Federal Communications Commission, OPP Working Paper Series No. 30, August, 1998.

[4] K. Werbach, "Digital Tornado: The Internet and Telecommunications Policy," Office of Plans \& Policy, Federal Communications Commission, Washington, D.C., OPP Working Paper Series No. 29, March, 1997.

[5] FCC, "In the Matter of Federal-State Joint Board on Universal Service, CC Docket No. 96-45, Report to Congress," Federal Communications Commission, Washington, D.C., FCC 98-67, April 10, 1998.

[6] FCC, "In the Matter of Inquiry Concerning the Deployment of Advanced Telecommunications Capability to All Americans in a Reasonable and Timely Fashion, and Possible Steps to Accelerate Such Deployment Pursuant to Section 706 of the Telecommunications Act of 1996, CC Docket No. 98-146, Notice of Inquiry," Federal Communications Commission, Washington, D.C., FCC 98-187, August 6, 1998.

[7] J. Weinberg, "The Internet and "Telecommunications Services", Access Charges, Universal Service Mechanisms and Other Flotsam of the Regulatory System," presented at Telecommunications Policy Research Conference, Washington, D.C., 1998.

[8] M. Kende, "The Digital Handshake: Connecting Internet Backbones," Office of Plans \& Policy, Federal Communications Commission, OPP Working Paper Series No. 32, September, 2000.

[9] R. Zakon, "Hobbes' Internet Timeline v5.0," http://www.isoc.org/zakon/Internet/History/HIT.html, Last accessed: December, 1999.

[10] J. Oxman, "The FCC and Unregulation of the Internet," Office of Plans \& Policy, Federal Communications Commission, OPP Working Paper Series No. 31, July, 1999.

[11] Congress, "Competition in Provision of Telecommunications Service," in Communications Act of 1934. Washington, D.C.: One Hundred and Fourth Congress of the United States, 1996, Sec 10.

[12] P. Huber, M. K. Kellogg, J. Thorne, and A. C. Schlick, "Long Distance Services," in Federal Telecommunications Law, 2nd ed. New York: Aspen Law and Business, 1999, pp. 739-740. 
[13] Congress, "Interconnection: General Duty of Telecommunications Carriers," in Communications Act of 1934. Washington, D.C.: One Hundred and Fourth Congress of the United States, 1996, Sec. 251(a).

[14] Y. Rekhter and P. Gross, "Application of the Border Gateway Protocol in the Internet," T.J. Research Center, IBM Corp., MCI, IETF RFC 1772, March, 1995.

[15] P. Milgrom, B. Mitchell, and P. Srinagesh, "Competitive Effects of Internet Peering Policies," presented at Telecommunications Policy Research Conference, Arlington, Virginia, 1999.

[16] S. Paltridge, "Internet Infrastructure Indicators," Working Party on Telecommunication and Information Service Policies, Directorate for Science, Technology, and Industry, Organisation for Economic Co-operation and Development (OECD), Paris, DSTI/ICCP/TISP(98)7/FINAL, October 28, 1998.

[17] G. C. Staple, "A Primer on Peering," in TeleGeography 1999: Global Telecommunications Traffic Statistics and Commentary. Washington, D.C.: TeleGeography, Inc., 1998, 128.

[18] R. Frieden, "When Internet Peers Become Customers: The Consequences of Settlementbased Interconnection," presented at Telecommunications Policy Research Conference, Arlington, VA, 1999.

[19] S. Blake, D. Black, M. Carlson, E. Davies, Z. Wang, and W. Weiss, "An Architecture for Differentiated Services," Network Working Group, Internet Engineering Task Force, Request for Comments (RFC) 2475, December, 1998.

[20] B. Teitelbaum, "QBone Architecture (v1.0)," Internet2 QoS Working Group, August, 1999.

[21] QoSForum, "Frequently Asked Questions about IP Quality of Service," Stardust Forums, Inc., http://www.qosforum.com/docs/faq/, Last accessed: December, 1999.

[22] E. Ellesson and J. Strassner, "Policy Framework Working Group," http://www.ietf.org/html.charters/policy-charter.html, Last accessed: December, 1999.

[23] DMTF, "Directory Enabled Network (DEN) FAQ," Distributed Management Task Force, Inc., http://www.dmtf.org/pres/rele/denfaq.html, Last accessed: December, 1999.

[24] Congress, "Interconnection: Obligations of All Local Exchange Carriers," in Communications Act of 1934. Washington, D.C.: One Hundred and Fourth Congress of the United States, 1996, Sec. 251(b).

[25] Congress, "Numbering Administration," in Communications Act of 1934. Washington, D.C.: One Hundred and Fourth Congress of the United States, 1996, Sec. 251(e). 
[26] FCC, "In the Matter of Local Competition Provisions in the Telecommunications Act of 1996, CC Docket No. 96-98; Interconnection between Local Exchange Carriers and Commercial Mobile Radio Service Providers, CC Docket No. 95-185, First Report and Order," Federal Communications Commission, Washington, D.C., FCC 96-325, August 8, 1996.

[27] V. Fuller, T. Li, J. Yu, and K. Varadhan, "Classless Inter-Domain Routing (CIDR): an Address Assignment and Aggregation Strategy," BARRNet, Cisco Systems, MERIT, OARnet, IETF RFC 1519, September, 1993.

[28] Y. Rekhter and T. Li, "An Architecture for IP Address Allocation with CIDR," T.J. Watson Research Center, IBM Corp., Cisco Systems, IETF RFC 1518, September, 1993.

[29] J. Kowal, "TeleGeography 2000: Global Telecommunications Traffic Statistics \& Commentary," . Washington, D.C.: TeleGeography, Inc., 1999.

[30] C. Shapiro and H. R. Varian, "Recognizing Lock-In," in Information Rules: A Strategic Guide to the Network Economy, 1st ed. Boston: Harvard Business School Press, 1999, pp. 109.

[31] Congress, "Regulation of Pole Attachments," in Communications Act of 1934. Washington, D.C.: One Hundred and Fourth Congress of the United States, 1996, Sec. 224.

[32] Metricom, "In the Matter of Promotion of Competitive Networks in Local Telecommunications Markets, WT Docket No. 99-271, Comments of Metricom, Inc. Before the Federal Communications Commission," 1999.

[33] Congress, "Bell Operating Company Entry Into InterLata Services: Specific Interconnection Requirements," in Communications Act of 1934. Washington, D.C.: One Hundred and Fourth Congress of the United States, 1996, Sec. 271(c)(2).

[34] A. Brown, "Telephone Number Mapping: ENUM Requirements," Internet Engineering Task Force, Internet Draft, November, 1999.

[35] P. Huber, M. K. Kellogg, J. Thorne, and C. S. Elwood, "Interconnecting Wireless Providers with Local Landline Networks," in Federal Telecommunications Law, 2nd ed. New York: Aspen Law and Business, 1999, pp. 941-942.

[36] D. D. Clark, "A Taxonomy of Internet Telephony Applications," presented at Telecommunications Policy Research Conference, Alexandria, VA, 1997.

[37] D. C. Sicker, "The effect of emerging signaling protocols on future telephony," CCH Power and Telecom Law, vol. March/April, 1999.

[38] FCC, "Statutory Definitions," in In the Matter of Federal-State Joint Board on Universal Service, CC Docket No. 96-45, Report to Congress. Washington, D.C.: Federal Communications Commission, 1998, par. 48. 
Notes

[1] Advance Research Projects Agency (ARPA) sent out the first Request for Proposals for ARPAnet in 1965, and ARPAnet was commissioned by the Department of Defense for research on networking in 1969 [9].

[2] National Science Foundation (NSF) funded establishment of NSFnet in 1986 to provide universities with high-speed network connections [9].

[3] NSF created InterNIC to provide directory and database services (via contract awarded to AT\&T), registration services (via contract awarded to Network Solutions, Inc.), and information services (via CERFnet contract to General Atomics) [9].

[4] Originally, four NAPs were created (in New York, Washington, D.C., Chicago, and San Francisco) and supported by NSF as part of the transition from the original U.S. government-financed Internet to a commercially operated Internet.

[5] The very high performance Backbone Network Service (vBNS) and Internet2 are NSF funded research networks that were initiated subsequent to the decommissioning of the original NSFnet in 1995.

[6] In 1970, the Commission approved MCI's application to offer long distance services as a common carrier. This required that AT\&T's local exchange services be accessible to MCI's long distance service so that callers (that connected to long distance services via local exchange services) could originate and terminate calls [12].

[7] To date, the Commission has issued no rulings on this matter.

[8] The Common Open Policy Service (COPS) protocol is one of several protocols that may be used for BB to BB communication [21].

[9] Such a requirement was imposed on Worldcom as a condition for the Department of Justice's approval of its merger with MCI.

[10] Cf Section 256 of the Act.

[11] See Comcast-@Home terms of service at http://www.comcastonline.com/subscriber-v3red.asp

[12] As discussed in the following section, the requirement for Number Portability has created a second name space.

[13] A system of regional number portability databases are to be managed by independent local number portability administrators. The costs of establishing number portability are to be borne by all telecommunications carriers [1].

[14] Routes are aggregated to combine the characteristics of several routes so that a single route can be advertised, thereby reducing the number of routes that need to be maintained by core providers employing default-route-free routing tables. In October 1999, there 
were an estimated 70,000 routes in these routing tables, a four-fold increase over 1994 [29].

[15] The American Registry for Internet Numbering (ARIN) has the authority to assign or allocate portable IP addresses, but increasingly relies upon large and established IP service providers to allocate hierarchical subsets of their IP address block to their downstream customers. The rationale for this policy is that more portable IP addresses cannot be aggregated and thus contribute to route growth. Prior to the early 1990's, ARIN assigned IP address blocks to organizations that requested them. Many of the large and established IP service providers were assigned IP address blocks during the reign of this policy. Under some circumstances, providers receive provider-independent (portable) addresses from ARIN.

[16] 190.10.0.0/16 is the IPv4/CIDR address block advertised by the exterior gateway for Provider A. The "/16" implies that the first 16 bits of the 32 bit address correspond to the network portion of the address. Provider A allocates the 190.10.80.0/21 address block to the customer, providing the customer with $2^{\wedge} 11$ or 2048 addresses; 32 bits minus 21 bits for network portion leaves 11 bits for customer use.

[17] http://www.netergynet.com/News-events/pr-archive/pr20000327a.html

[18] In the 1980's, several Bell companies refused to provide unaffiliated wireless carriers with Type 2 interconnection. They were offered Type 1, which was more limited in terms of transmission quality, permissible billing arrangements, and efficient use of switching facilities [35]. 